\title{
Assigning of land location and land price to land parcel using ArcGIS engine
}

\author{
Duc Trong Tran* \\ University of Technology - VNU-HCM, Ho Chi Minh City, Vietnam
}

ARTICLE INFO

Article history:

Received $15^{\text {th }}$ Sept. 2020

Revised $05^{\text {th }}$ Jan. 2021

Accepted 28 $8^{\text {th }}$ Jan. 2021

\section{Keywords:}

ArcGIS Engine,

GIS,

Land location,

Land price.

\section{ABSTRACT}

Assigning a state price to each land parcel is a frequent and yet important task in the state management of land parcels. Land price is issued for each street. For each street, land price is divided according to level of location $1,2,3$ and 4. Parcel is assigned to which location level depending on its walking distance to nearest street, and passed minimum alley's width, etc. The task of valuing land parcels is cumbersome because the number of land parcels to be priced is huge. To alleviate this burden for government staff, a step by step processing model is developed to automatically determine the location level of a particular parcel. Using ArcGIS Engine library and VB.NET programming language, the steps in the proposed model are built into functions in a specialized module for land valuation. Experiment in assigning location level and land prices of Tam Hiep ward, Bien Hoa city, Dong Nai province shows that 91,73\% of parcels are assigned the same location level as the location on the issued land location map. The experiment demonstrates the effectiveness and correctness of the proposed model in automatically determining location levels and corresponding prices of land parcels.

Copyright (C) 2021 Hanoi University of Mining and Geology. All rights reserved.

${ }^{*}$ Corresponding author

E-mail: ttduc@hcmut.edu.vn

DOI: 10.46326/JMES.2021.62(1).04 


\title{
Tạp chí Khoa học Kỹ thuật Mỏ - Địa chất
}

Trang điện tử: http://tapchi.humg.edu.vn

\section{Định vị trí và giá cho từng thửa đất sử dụng ArcGIS Engine}

\author{
Trần Trọng Đức* \\ Truờng Đại học Bách Khoa - ĐHQG-TPHCM, TP. Hồ Chí Minh, Việt Nam
}

\section{THÔNG TIN BÀI BÁO T TÓM TẮT}

\section{Quá trình:}

Nhận bài $15 / 9 / 2020$

Sưa xong 05/01/2021

Chấp nhận đăng 28/01/2021

\section{Tù̀ khóa:}

ArcGIS Engine,

Giá đất,

GIS,

Vị trí đất
Định giá đất đến tùng thưa đất là một nhiệm vụ thường xuyên và quan trọng trong hoạt động quân lý Nhà nước về đất đai. Giá đất được quy định cho từng tuyến đường. Ớ mỗi tuyến đường giá đất được xác định theo vị trí 1,2, 3 và 4. Thửa đất đước xác định thuộc vi trí nào tùy thuộc khoảng cách di chuyển tù̀ thửa đất đến tuyến đường gần nhất và độ rộng nhỏ nhất của hẻm đã di chuyển qua,... Nhiêm vụ định giá đất trở nên nặng nề do số lượng thưa đất cần xác định giá rất lớn. Để giảm nhe gánh nặng này cho những người làm công tác định giá đất, một mô hình xử lý từng bước được phát triển để tự động xác định cấp vị trí của thửa đất. Sử dung thu viện ArcGIS Engine và ngôn ngũ lập trình VB.NET, các bước thực hiện trong mô hình đề xuất được xây dựng thành các chức năng trong một mồ-đun chuyên biệt phục vư định giá đất. Kết quả thực nghiệm áp giá đất lên phường Tam Hiệp, Tp. Biên Hòa, tỉnh Đồng Nai cho thấy 91,73\% thửa đất đã được tự động phân vị trí giống với vị trí trên bản đồ vị trí đất đã ban hành. Kết quả thực nghiệm chứng tỏ tính hữu hiệu và đúng đắn của mô hình trong xác định tự động vị trí và giá của thửa đất.

C 2021 Trường Đại học Mỏ - Địa chất. Tất cả các quyền được bảo đảm.

\section{Mở đầu}

Thông thường sau mỗi năm năm, Ủy ban nhân dân cấp tỉnh, thành phố ban hành bảng quy định giá đất cho từng đường giao thông chính và các loại vị trí khác nhau thuộc tuyến đường. Tùy thuộc vào quy định ban hành, mỗi thửa đất sẽ phân vào 1 trong bốn vị trí thuộc một đường giao thông xác định. Công tác định vị trí và tương ứng là giá cho các thửa đất gặp nhiều khó khăn do số lượng thửa đất cần định giá tại một đơn vị hành chính là rất lớn. Trong phần mềm GIS - ví dụ

*Tác giả liên hệ

E-mail: ttduc@hcmut.edu.vn

DOI: 10.46326/JMES.2021.62(1).04
ArcGIS - đã có sẵn một số công cụ xử lý dữ liệu không gian và do đó một số phần việc trong quá trình định giá đất có thể được thực hiện dễ dàng và nhanh chóng bằng cách sử dụng các công cụ có sẵn này, ví dụ tìm ra những thửa đất nằm trên mặt tiền đường giao thông hoặc tính khoảng cách từ thửa đất ra đến đường giao thông xác định. Một số phần việc trong quá trình định giá đất gây khó khăn hơn cho người làm công việc định giá đất, ví dụ từ một thửa đất có thể đi ra đến nhiều đường giao thông, thì phải xác định xem tuyến nào là tuyến ngắn nhất và tuyến ngắn nhất đó đi qua hẻm có độ rộng hẹp nhất là bao nhiêu. Quá trình định giá đất do vậy không chỉ tốn nhiều thời gian mà có thể dẫn đến sai sót nếu không được thực hiện một cách hợp lý. 
Để giải quyết vấn đề, Lê Văn Trung (2012) đã mô tả khái quát các chức năng của phần mềm GIS cung cấp công cụ lưu trữ, cập nhật và phân tích trong lập bản đồ giá đất, nhưng không đề cập chi tiết cách tính giá đất. Các bước của mô hình xử lý tự động xác định vị trí và giá đất cho từng thửa đất đã được mô tả bởi Trần Trọng Đức và Nguyễn Thế Bách (2011). Vào thời điểm đó, các bước của mô hình xử lý được phát triển dựa trên quy định giá đất ban hành theo QĐ 79/2010/QĐ-UBND tỉnh Đồng Nai. Theo quyết định đó, thửa đất được xác định vị trí dựa chủ yếu vào khoảng cách đến đường và dựa vào điều kiện thửa đất có nằm trên hẻm nối trực tiếp hay gián tiếp thông qua một hẻm khác đến tuyến đường. QĐ 49/2019/QĐ-UBND tỉnh Đồng Nai ban hành ngày 31 tháng 12 năm 2019 có những thay đổi đáng kể về cách thức xác định vị trí của thửa đất. Bài báo này đề xuất mô hình xử lý mới để tự động xác định vị trí của thửa đất theo hướng dẫn của quyết định số 49/2019/QĐ-UBND. Mô hình xử lý được thực hiện dựa trên ArcGIS Engine và ngôn ngữ lập trình VB.NET và được tiến hành thực nghiệm trong định giá đất ở đô thị của các thửa đất thuộc phường Tam Hiệp, Tp. Biên Hòa, tỉnh Đồng Nai.

\section{Phương pháp nghiên cứu}

\subsection{Quy tắc xác định vị trí và giá đất}

Đối với khu vực nghiên cứu, vị trí của các thửa đất thuộc loại đất ở đô thị, được xác định dựa trên QĐ 49/2019/QĐ-UBND tỉnh Đồng Nai có thể được tổng kết như trong Bảng 1. Thửa đất không thuộc các trường hợp tham chiếu trong Bảng 1 (trừ các thửa đất thuộc vị trí 1 ) được xác định ở vị trí 4 , tính theo đường gần nhất và có mức giá cao nhất đến thửa đất cần định giá.

\section{Bảng 1: Các vị trí đất ở 2, 3, 4 tại đô thị thuộc tỉnh Đồng Nai.}

\begin{tabular}{|c|c|c|c|}
\hline Khoảng cách từ thửa & \multicolumn{3}{|c|}{ Bề rộng hẻm } \\
\cline { 2 - 4 } $\begin{array}{c}\text { đất đến đường giao } \\
\text { thông chính }\end{array}$ & $\geq 5 \mathrm{~m}$ & $\geq 3 \div<5 \mathrm{~m}$ & $<3 \mathrm{~m}$ \\
\hline$\leq 200 \mathrm{~m}$ & VT2 & VT2 & VT3 \\
\hline$>200 \div \leq 400 \mathrm{~m}$ & VT2 & VT2 & VT4 \\
\hline$>400 \div \leq 600 \mathrm{~m}$ & VT2 & VT3 & VT4 \\
\hline$>600 \mathrm{~m}$ & VT3 & VT4 & VT4 \\
\hline
\end{tabular}

Trường hợp thửa đất vị trí 1 có chiều sâu tính từ mốc lộ giới >50 m thì được tính theo quy định sau: i) Từ mốc lộ giới đến $\leq 50$ m: tính bằng 100\%; ii) Từ sau mét $50 \div \leq 100 \mathrm{~m}$ : tính bằng $80 \%$ và iii) Từ sau mét thứ 100 đến hết chiều sâu thửa đất: tính bằng $50 \%$ giá đất vị trí 1 của đường đó. Ngoài ra, giá đất phi nông nghiệp tại các vị trí 2,3 , 4 nếu thuộc hẻm có nền nhựa, bê tông xi măng thì nhân với hệ số 1 ; nếu thuộc hẻm có nền đất, cấp phối thì nhân với hệ số 0,8 .

\subsection{Mô hình tính toán vị trí và giá đất}

Mô hình tính toán vị trí và giá các loại đất có thể được phân làm 3 bước xử lý chính như sau:

- Bước 1 : xác định vị trí 1 và giá tương ứng cho từng thửa đất trên đường giao thông chính:

Bắt đầu quá trình bằng cách duyệt qua từng đường giao thông chính từ giá thấp nhất đến cao nhất. Khi duyệt một đường giao thông, sẽ tìm kiếm tất cả các thửa đất giao với nó, sau đó chuyển tên đường đến từng thửa đất đã tìm thấy và gán vị trí cấp 1 cho các thửa đất này. Truy vấn giá đất theo tên đường trong bảng giá đất và tiến hành gán giá đất cho các thửa đất. Quá trình này sẽ lặp lại cho tất cả đường giao thông. Việc gán giá từ thấp đến cao sẽ đảm bảo các thửa đất nằm ở giao của nhiều đường giao thông chính sẽ được gán giá cao nhất. Trường hợp thửa đất vị trí 1 có chiều sâu tính từ mốc lộ giới $>50 \mathrm{~m}$ thì từ mỗi đường giao thông duyệt sẽ tiến hành xây dựng đa vùng đệm với bán kính lần lượt 50 m, 100 m, 200 m. Tiến hành tìm diện tích của phần giao của từng hình thể vùng đệm con với hình thể thửa đất và xác định giá của phần hình thể theo quy định đã mô tả ở mục 2.1.

- Bước 2: xác định vị trí $2,3,4$ và giá đất cho thửa đất tiếp xúc dọc theo đường hẻm:

Bắt đầu quá trình bằng cách duyệt qua từng đường hẻm. Khi duyệt một đường hẻm, tìm kiếm các thửa đất (trừ các thửa đất đã được định vị trí 1) giao với đường hẻm. Đối với mỗi thửa đất được tìm thấy, tìm hai góc thửa đất - vị trí được cho là có góc gần vuông $\left(90^{\circ} \pm 5^{\circ}\right)$ - gần nhất với đường hẻm. Sử dụng mạng lưới giao thông, tìm tuyến đường đi ngắn nhất từ hai gốc thửa đất ra đến đường giao thông chính. Hai tuyến đường đi của cùng một thửa đất được so sánh với nhau để chọn ra tuyến ngắn nhất. Đối với mỗi tuyến đường ngắn nhất tìm thấy, tìm độ rộng hẻm nhỏ nhất cũng như kết cấu hẻm mà tuyến đường đi qua. Từ thông tin khoảng cách, độ rộng hẻm nhỏ nhất và quy định từ Bảng 1 xác định vị trí của thửa đất. Kết cấu hẻm đã đi qua giúp xác định hệ số nhân là 1 hoặc 0,8 . 
Tên đường mà tuyến đường đi từ thửa đất đến giúp xác định giá đất đơn vị của thửa đất.

- Bước 3: xác định vị trí 4 và giá đất cho các thửa đất chưa xử lý còn lại:

Bắt đầu quá trình bằng cách duyệt qua từng thửa đất chưa được chỉ định vị trí. Đối với mỗi thửa đất, tìm kiếm đường giao thông hoặc hẻm gần nhất. Nếu tìm thấy đường giao thông gần nhất, thửa đất được chỉ định vị trí 4 , tên đường phố và giá đất tương ứng. Nếu tìm thấy hẻm gần nhất thì tìm điểm gần nhất trên hẻm và tìm đường đi ngắn nhất từ điểm ra đến đường giao thông. Quá trình xác định hệ số, tên đường từ tuyến đường đi ngắn nhất và giá đất được thực hiện giống như mô tả ở bước 2.

Sơ đồ thuật toán mô hình tính toán vị trí và giá đất được tổng kết trong Hình 1.

\section{Kết quả và thảo luận}

\subsection{Co' sở dũ liệu}

Để làm cơ sở tính toán vị trí và giá của thửa đất, dữ liệu sau đây được sử dụng:

- Lớp thửa đất. Các thuộc tính bao gồm: ID của thửa đất, tên đường, tên đoạn, DT_PNN1 (diện tích phi nông nghiệp 1), DT_PNN2, DT_PNN3, DT_
PNN4, giá đất đơn vị, GiaPVT1 (giá đất phi nông nghiệp 1), GiaPVT2, GiaPVT3, GiaPVT4, hệ số, độ dài đường đi, Giá đất tổng hợp.

- Lớp mặt đường giao thông. Thuộc tính bao gồm loại mặt ('đường' hoặc 'hẻm').

- Lớp tim đường giao thông được sử dụng để xây dựng mạng đường giao thông. Các thuộc tính bao gồm: tên đường, tên đoạn đường, kết cấu, độ rộng.

- Bảng thuộc tính chứa đơn giá đường giao thông. Các thuộc tính bao gồm: tên đường, tên đoạn, giá vị trí $1,2,3$ và 4 .

- Bảng thuộc tính chứa các quy tắc quyết định như được mô tả trong Bảng 1. Các thuộc tính bao gồm: khoảng cách tối thiểu, tối đa, chiều rộng hẻm, cấp vị trí.

Dữ liệu trong hệ thống được xây dựng dựa trên mô hình cơ sở dữ liệu Geodatabase (Michael Zeiler, 1999).

\subsection{Thiết kế chức năng của úng dụng}

Một mô-đun chuyên biệt phục vụ công tác định giá đất được thiết kế và xây dựng để chuyển các bước tính toán trong mô hình thành các công cụ trong phần mềm. Các chức năng trong mô-đun

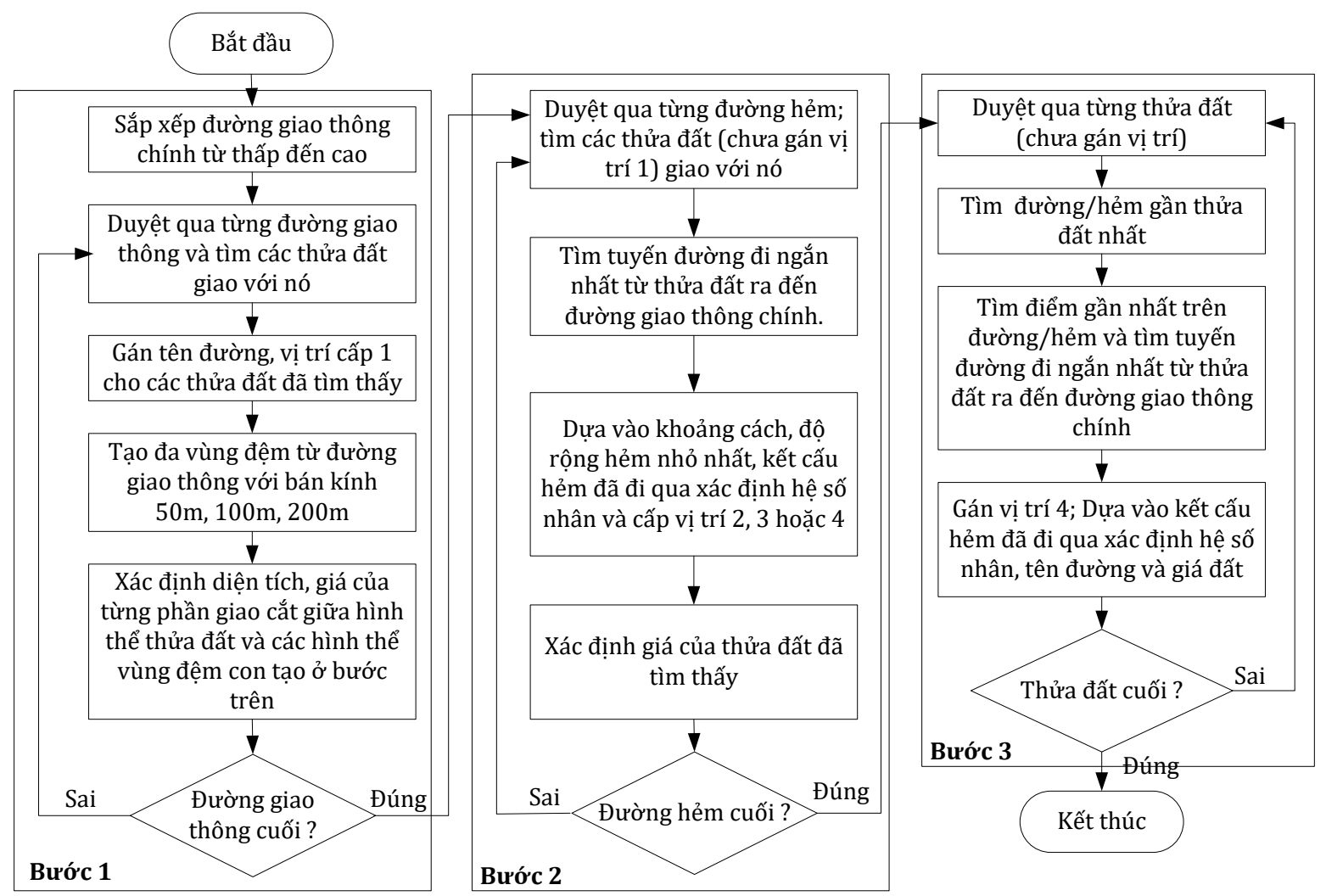

Hình 1. Sơ đồ thuật toán mô hình tính toán vị trí và giá đất. 
được thể hiện như trong Hình 2. Vai trò của các chức năng trong mô-đun này như sau:

- Cập nhật thông tin cơ sở: cho phép nhân viên chỉnh sửa bảng giá đường và các điều kiện ra quyết định trong Bảng 1.

- Tính vị trí và giá đất: cho phép tính vị trí và giá đất dựa trên dữ liệu cơ bản và dữ liệu của thửa đất. Nó bao gồm ba chức năng tương ứng với ba bước của mô hình xử lý.

- Truy vấn thông tin thửa đất: cho phép truy vấn thông tin tính toán liên quan đến thửa đất và hiển thị tuyến đường đi từ thửa đất đến đường giao thông chính gần nhất.

\subsection{Thực nghiệm}

Mô-đun ứng dụng được phát triển dựa trên ngôn ngữ lập trình VB.Net và ArcGIS Engine 10.2.2 (Michael Zeiler, 2001; ESRI, 2004). Mô-đun được sử dụng để gán vị trí và đơn giá cho các thửa đất của phường Tam Hiệp, TP. Biên Hòa.

Hình 2 minh họa giao diện của ứng dụng GIS với mô-đun định giá đất và dữ liệu của khu vực nghiên cứu. Các thửa đất được thể hiện màu theo vị trí $1,2,3,4$. Dư liệu này được cung cấp bởi phường Tam Hiệp.

\subsubsection{Kết quả xử lý}

Sử dụng các công cụ có trong mô-đun định giá đất, 6421 thửa đất ở đô thị thuộc khu vực nghiên cứu đã được xác định vị trí 1, 2, 3, 4 . Hình 3 minh họa kết quả xác định vị trí thửa đất. Các thửa đất được thể hiện màu theo vị trí 1, 2, 3, 4 giống như thể hiện trong Hình 2 để thuận tiện so sánh với bản đồ vị trí đất thực hiện bởi cơ quan địa phương.

\subsubsection{Thò̀i gian xử lý}

Không tính đến thời gian biên tập, chuẩn bị dữ liệu đầu vào cho chương trình định vị trí và giá đất, thời gian đã sử dụng để chạy các bước trong mô hình như sau:

- Bước 1: 26 giây.

- Bước 2: 15 phút 02 giây.

- Bước 3: 17 giây.

Tổng thời gian thực thi của mô hình là khoảng 16 phút.

\subsection{3. Độ chính xác}

Để đánh giá chất lượng của mô hình xử lý, các thửa đất được định vị trí bởi mô hình được so sánh với các thửa đất tương ứng được định vị trí trên bản đồ vị trí đất đã ban hành.

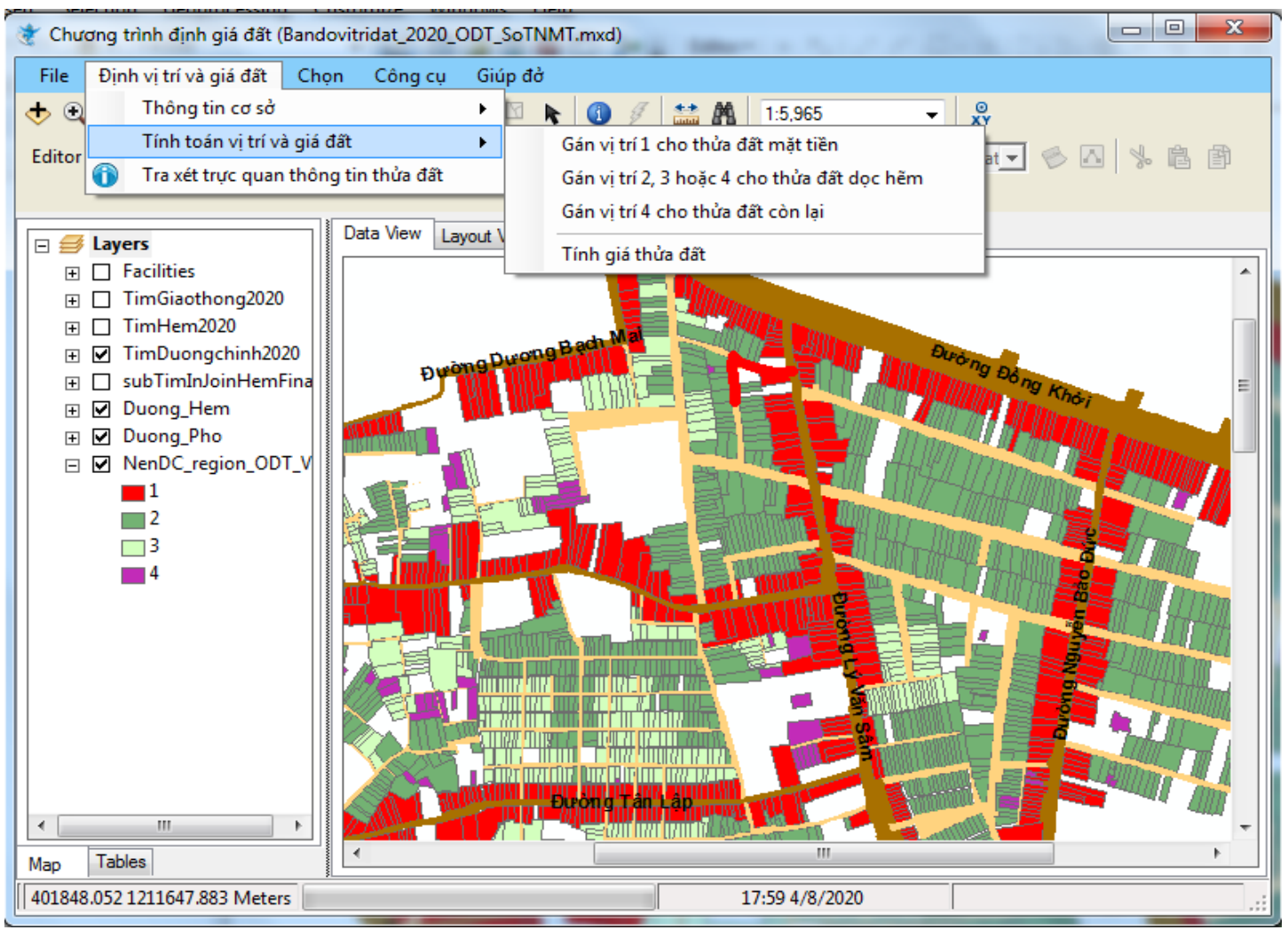

Hình 2. Giao diện của úng dụng GIS với mô-đun định giá đất và dũ liệu thưa đất. 


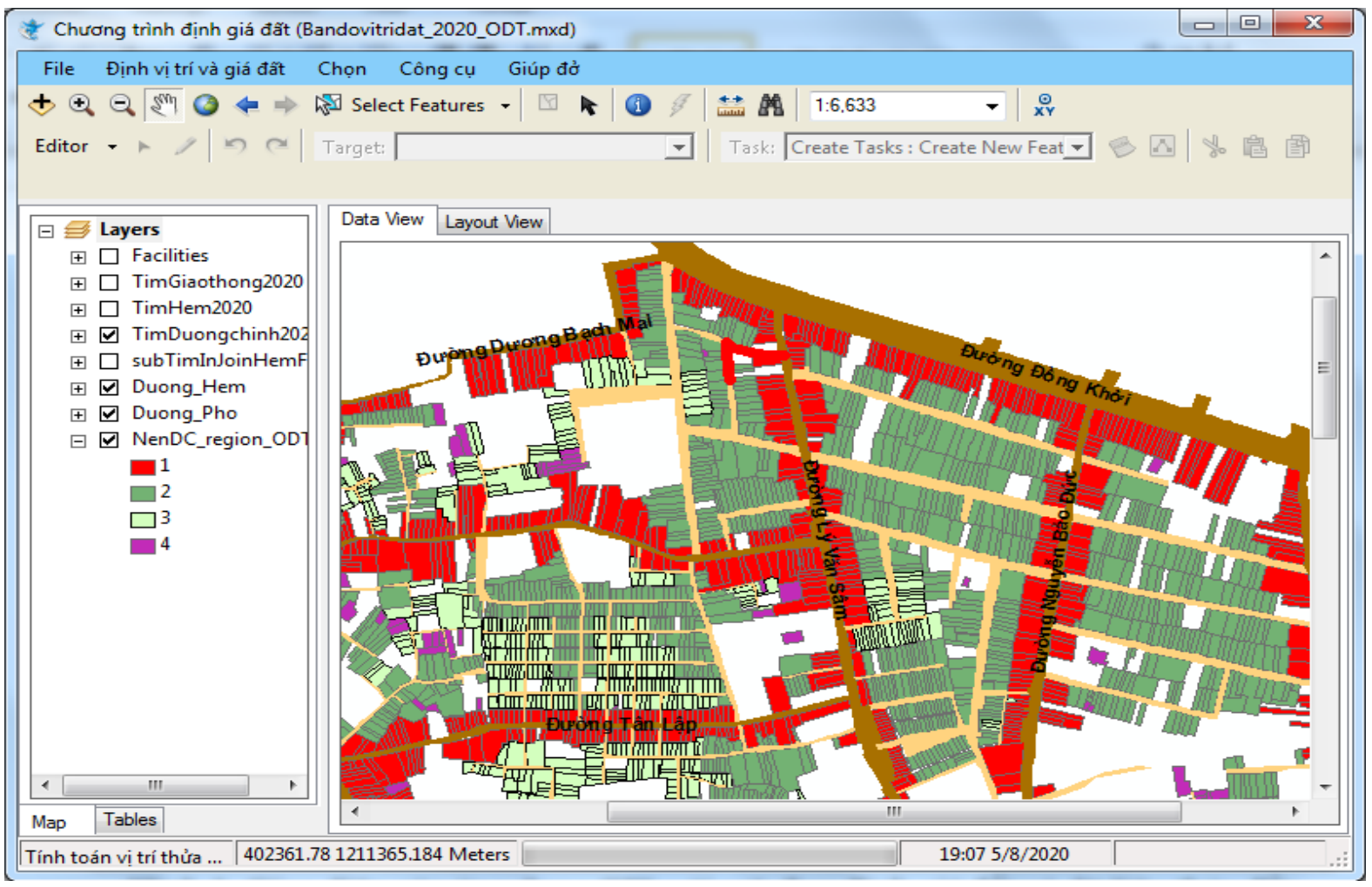

Hình 3. Kết quả xác định vị trí thửa đất theo mô hình xử lý đã đề xuất.

Kết quả so sánh được tóm tắt trong ma trận sai số ở Bảng 2.

Bảng 2. Ma trận sai số của các kết quả định vị trí.

\begin{tabular}{|c|c|c|c|c|c|}
\hline & \multicolumn{4}{|c|}{$\begin{array}{c}\text { Vị trí thửa đất trên bản đồ vị } \\
\text { trí đất đã ban hành }\end{array}$} \\
\hline & & Vị trí 1 & Vị trí 2 & Vị trí 3 & Vị trí 4 \\
\hline \multirow{4}{*}{ 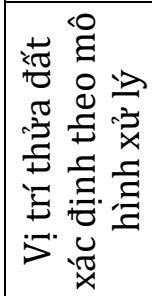 } & Vị trí 1 & 1825 & 3 & 0 & 1 \\
\hline & Vị trí 2 & 3 & 2199 & 145 & 44 \\
\hline & Vị trí 3 & 0 & 132 & 1452 & 64 \\
\hline & Vị trí 4 & 0 & 83 & 59 & 411 \\
\hline
\end{tabular}

Tỉ lệ phần trăm phù hợp giữa 2 phương pháp $(1825+2199+1452+411) * 100 / 6421=91,73 \%$.

Vấn đề là cần phải xác định xem trong 8,23\% vị trí không tương đồng, phương pháp nào xác định vị trí chính xác hơn. Do không có điều kiện để thảo luận với cơ quan địa phương về các vị trí có sự khác biệt, tác giả chỉ có thể đưa ra một số minh họa có thể tự kiểm chứng dựa trên văn bản quy định về định vị trí để cho thấy tính chính xác hơn của phương pháp tự động xác định vị trí theo mô hình so với bản đồ vị trí đất đã ban hành.

- Minh họa 1: Thửa đất trên Hình 4a có đường ranh được đánh dấu bằng đường màu xanh được định vị trí 1 bởi chương trình xử lý, trong khi lại được xác định là vị trí 4 trên bản đồ vị trí đất đã ban hành ở Hình 4b. Quan sát trên bản đồ, có thể thấy rõ thửa đất nằm trên mặt tiền đường nên theo quy tắc quyết định, thửa đất phải thuộc vị trí 1 và như vậy mô hình xử lý cho ra kết quả định vị trí chính xác. Lý do cơ quan địa phương xác định thửa đất này là vị trí 4 có thể là do thửa đất này lùi vào khoảng $5 \mathrm{~m}$ và không tiếp xúc với tuyến đường.

- Minh họa 2: Quan sát các thửa đất nằm bên trong hình ellipse đứt đoạn thuộc Hình $4 \mathrm{a}$, có thể thấy 1 thửa đất được xếp vị trí 3 , do thửa đất nằm trên mặt hẻm có độ rộng $1,6 \mathrm{~m}$ và cách tuyến đường khoảng $30 \mathrm{~m}$. Theo quy tắc quyết định trong Bảng 1, mô hình xử lý đã cho ra kết quả định vị trí chính xác hơn so với vị trí 4 trên bản đồ vị trí đất đã ban hành.

- Minh họa 3: Các thửa đất nằm dọc theo một hẻm có độ rộng $6 \mathrm{~m}$, khoảng cách xa nhất từ thửa đất ra đến đường Đồng Khởi là $75 \mathrm{~m}$ đã được xác định vị trí 2 theo mô hình xử lý (Hình 5a). 

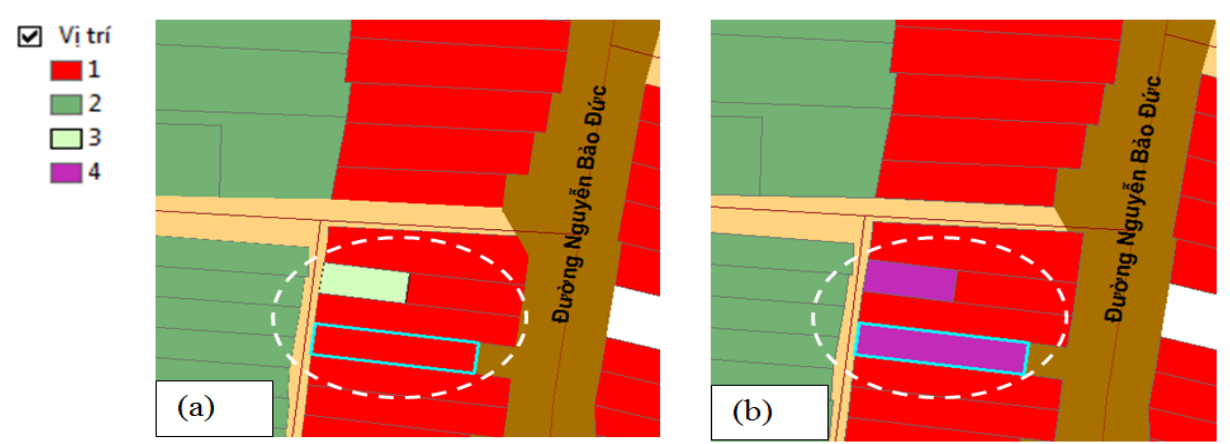

Hình 4. Minh họa 1 và 2 về sự khác biệt kết quả định vị trígiữa mô hình xử lý (a) và bản đồ vị trí đất đã ban hành (b).
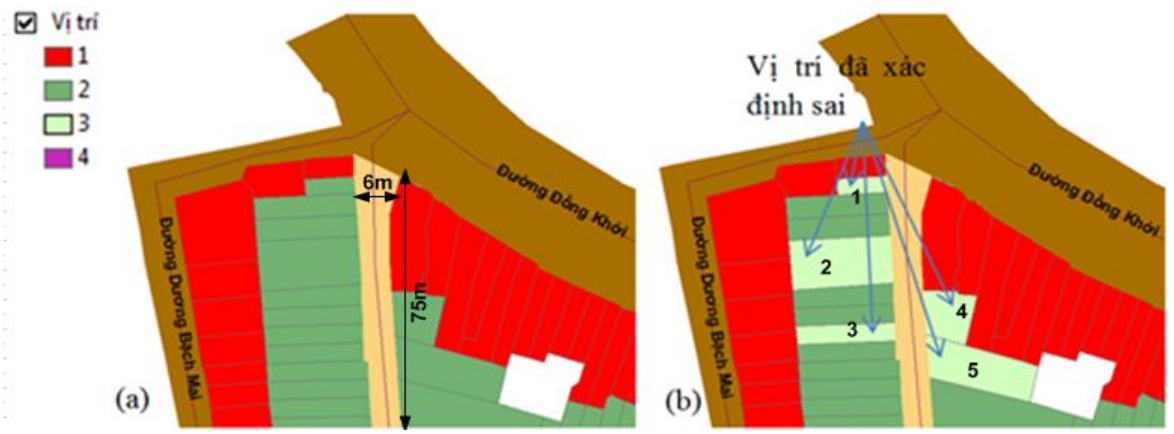

Hình 5. Minh họa 3 về sự khác biệt kết quả định vị trígiữa mô hình xử lý (a) và bản đồ vị trí đất đã ban hành (b).

Theo quy tắc quyết định trong Bảng 1 , mô hình xử lý đã cho ra kết quả định vị trí chính xác. Như vậy, các thửa đất đánh số $1,2,3,4,5$ có vị trí 4 trên Hình $5 b$ trên bản đồ vị trí đất đã ban hành là sai.

\subsubsection{Truy vấn thông tin}

Để cho phép người dùng của hệ thống kiểm tra kết quả xác định vị trí thửa đất, một công cụ tương tác được phát triển. Khi sử dụng công cụ này, chỉ cần nhấp chọn vào một thửa đất trên bản đồ, một hộp thoại sẽ xuất hiện hiển thị thông tin thuộc tính chi tiết về kết quả định vị trí thửa đất, đồng thời tuyến đường đi từ thửa đất đến đường giao thông chính gần nhất cũng được hiển thị như trong Hình 6.

\section{Kết luận}

Việc xác định vị trí và giá đất cho số lượng lớn thửa đất trong một đơn vị hành chính là một nhiệm vụ tốn thời gian với khả năng sai sót cao. Nghiên cứu này đề xuất một mô hình xử lý và cụ thể hóa mô hình thành một mô-đun định giá đất.

Sử dụng các công cụ có trong mô-đun định giá đất, 6421 thửa đất ở đô thị thuộc khu vực nghiên cứu đã được tự động xác định vị trí. 91,73\% thửa đất được xác định có cùng vị trí và giá đất như được cung cấp bởi cơ quan địa phương cho thấy ứng dụng tiềm năng cao của mô hình.

Tại một số vị trí có sự khác biệt, tiến hành tự kiểm chứng - dựa trên văn bản nhà nước đã quy định về định vị trí - cho thấy tính chính xác hơn của phương pháp tự động xác định vị trí theo mô hình so với bản đồ vị trí đất đã ban hành. Không tính đến thời gian biên tập, chuẩn bị dữ liệu đầu vào cho chương trình định vị trí và giá đất, thời gian định vị trí và giá đất cho 6421 thửa đất là vào khoảng 16 phút. Xem xét lượng thời gian mà nhân viên phải bỏ ra nếu thực hiện cùng khối lượng công việc bằng cách sử dụng kết hợp các chức năng có sẵn trong phần mềm GIS thông dụng và thực hiện thủ công, có thể thấy một lợi ích rất rõ ràng mà nhân viên có thể hưởng lợi khi sử dụng mô hình xử lý được đề xuất này. Bên cạnh mô-đun tự động xác định vị trí, một công cụ truy vấn thông tin thửa đất được phát triển, cho phép chọn một thửa đất trên bản đồ để xem lại các giá trị đánh giá đã đạt được cũng như xem lại tuyến đi từ thửa đất ra đến đường giao thông chính đã được xác định. Việc xem lại các giá trị đã đánh giá giúp người sử 


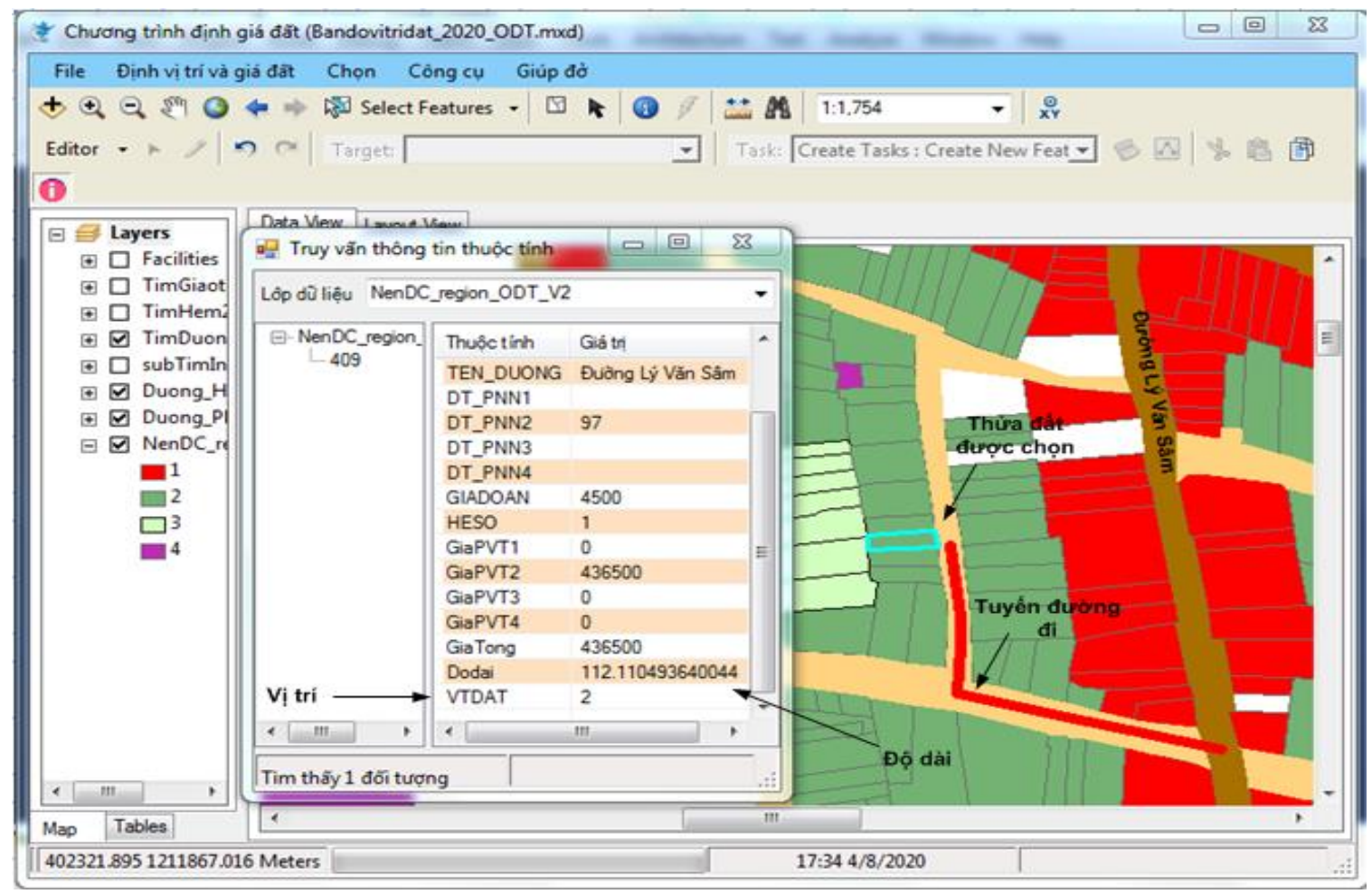

Hình 6. Kết quả tra xét thông tin thửa đất.

dụng hoặc nhân viên có thể kiểm chứng và từ đó có được sự tin cậy về mức độ chính xác của vị trí được xác định.

\section{Tài liệu tham khảo}

ESRI, (2004). ArcGIS® Engine developer guide, ESRI Press. 41 - 56.

Le Van Trung. (2012). GIS for mapping land price of the Tien Giang province, International Symposium on GeoInformatics for Spatial- InfraStructure Development in Earth and Allied Sciences, 2012. http://gisws.media.osakacu.ac.jp/gisideas12/viewpaper.php?id=464

Michael Zeiler. (2001). Exploring ArcObjects, vol. 1 \& 2, ESRI Press. 727-976.
Michael Zeiler. (1999). Modeling our world, ESRI guide to Geodatabase design, ESRI Press. 1 - 21.

Tran Trong Duc, Nguyen The Bach. (2011). Valuation of land parcel using GIS and ArcGIS Engine, Asia Geospatial Forum, Jakarta, Indonesia. 67.

UBND tỉnh Đồng Nai. (2010). Quyết định số 79/2010/QĐ-UBND tỉnh Đồng Nai về việc ban hành Quy định về giá các loại đất trên địa bàn tỉnh Đồng Nai năm 2011. 1-6.

UBND tỉnh Đồng Nai. (2019). Quyết định số 49/2019/QĐ-UBND tỉnh Đồng Nai về việc ban hành Quy định về giá các loại đất trên địa bàn tỉnh Đồng Nai năm 2019. 3-5. 